\title{
Perceptions of Students on Culture and Its Impact on Web-based Information Seeking at Solusi University in Zimbabwe
}

\author{
Bongani Ngwenya* \\ Faculty of Business, Solusi University, Bulawayo, Zimbabwe \\ *Corresponding author: nbongani@gmail.com,ngwenyab@solusi.ac.zw \\ Received February 23, 2013; Revised March 21, 2013; Accepted April 26, 2013
}

\begin{abstract}
The objective of this study was to identify cultural implications and differences through the perceptions of postgraduate students (male and female) at Solusi University, in Zimbabwe and assess the cultural implications and cultural differences` impact on information seeking, management and evaluation in the information environment and information practices, of an institution of higher learning. Literature has shown that there are differences between the success and failure factors in the developed and developing countries with regard to the development and use of Web-based or online information sources for learning purposes in Universities. There is very little literature, and evidence of attention given to this area of study in Zimbabwe in particular. This study is build on the premise that "information seeking" is socio-culturally bounded and that the success of use of Web-based information is highly related to - if not found at, the intersection between the implied by the perceptions of students, that is, information seekers and learners and the technology applied to achieve the desired information search outcomes. The data were collected by use of an instrument of a questionnaire that was administered among postgraduate students at Solusi University, in Zimbabwe, in 2011. The data were analysed quantitatively with SPSS version17.0 for Windows using mainly cross-tabulations and Chi-squared tests. The statistically significant differences focused on the general Web-based information seeking, management and evaluation in this information environment, and information practices used within the Solusi University. The conclusions drawn from the study were that cultural differences and implications influence the seeking of Web-based learning information and that the impact of cultural differences and implications should be examined more thoroughly in future studies, which should apply both qualitative and quantitative methods.
\end{abstract}

Keywords: information seeking, management and evaluation, Web-based or online, cultural differences, cultural implications

\section{Introduction}

The Internet has changed the way people of all ages seek, manage and evaluate information on the Web [1]. Literature suggests an ongoing paradigm shift in the realm of the Internet to Web 2.0, in other words, to more dynamic sources and interactive content, that seems to going to change people's information behaviour even more in future [2]. The Internet is a vast resource of Webbased or online information seeking and services. There is, however, a great lack of empirical research on cultural implications and cultural differences and their impact on information seeking, management and evaluation in related information environments. Moreover, empirical studies aiming to identify cultural differences and cultural implications in information environments like universities in Zimbabwe are rare.

This paper seeks to add to the body of knowledge of cultural differences and cultural implications in information behaviour. An earlier study of interest to this researcher, on Web-based information seeking has involved perceptions of Finnish university students [3]. The aim of this particular or current study is to ascertain how cultural implications and cultural differences impact on Internet use, or Web-based information seeking, management and evaluation by university students in a developing country`s university as an information environment.

The researcher focuses on three questions:

Information environments: which sources form the a) general and b) Web-based information environments of Solusi postgraduate university students?

Information practices: is Web-based information sought actively or encountered by chance? Which topical areas of information are sought actively and which are encountered?

Cultural differences and implications: is it possible to identify cultural differences and cultural implications in the information behaviour of the postgraduate Solusi university students? If so, are these differences and implications primarily related to the information environments or to the two types of information practices applied in this study? 
In the order of consideration, the paper begins with elaboration of Web-based information seeking, management and evaluation, with special focus on cultural differences and cultural implications and continues with the theoretical framework on information environments and practices. This is followed by a description of the research methodology, data analysis, conclusion and recommendations for further future studies.

\section{Literature Review and Theoretical Framework}

This section presents the theoretical framework, developed from literature upon which the concepts or themes of the study were based.

Web-based Information Seeking and Culture. There is no doubt that Internet is one of the most popular information sources [4]. Various features affect Webbased information seeking. These include sex, level of education [5], Internet self-efficacy [6] and e-information literacy, that is, the ability to use electronic information resources when addressing information need problems [7]. Earlier research indicates that cultural issues and implications also affect Web-based information seeking, management and evaluation $[8,9]$.

In this study Solusi University postgraduate students (respondents) of different cultural backgrounds are compared to the majority Zimbabwean students (respondents). It is important to note this distinction in cultural differences [10]. These differences include, for example, emphasizing the significance of the social environment as a determinant of self, which emerges as self-effacing behaviour [11]. This collaterally emphasizes the welfare of the group and consensus among its members [12], whether the group consists of the family members or workmates [13]. These features lead to a tendency to express feelings through action, not words [12]. Most of these features also appear to concern ethnic groups of Zimbabwean origin [8].

The user rates of the Internet are similar in most African countries. More than $80 \%$ of Zimbabweans and South Africans for example use the Internet regularly and the percentage of 15 to 29 year-old Internet users in Zimbabwe and South Africa is almost 100. This differs with what obtains in Finland for example [14]. In countries like Japan for example about $75 \%$ of Japanese use the Internet and the user rate for younger population, aged 13 to 29 , is over $95 \%$ [15]. However, there are some cultural differences in the use of the Internet. Japanese tend to use the Internet anonymously, for example to connect with the aid of the Internet to real-life strangers and to use the Internet primarily at home for private purposes, whereas Africans are more prone to make themselves known to other users and they also trust other users more [16].

In developed countries it is claimed that Internet-based programmes and tools for the general public help people to acquire lots and lots of information, for example if they are structured and offer personalized information on a variety of personal issues, and behavioural strategies and are used frequently $[17,18]$. There is, however, a great lack of empirical research on Web-based information practices in developing countries such as Zimbabwe and related information environments like universities [19]. Moreover, empirical studies aiming to identify cultural differences and cultural implications in information behaviour are rare in Zimbabwe in particular.

Despite the success of the Internet information seeking, management and evaluation programmes, there are mixed findings on the efficacy of the Internet as a medium for information satisfaction [20]. Most studies also report changes only in self-reported outcomes, such as opinions and certain social habits [21].

Information Environments and Practices. In this paper the researcher considers the Internet as an information channel for various types of information sources, from which the information user may choose suitable sources according his or her information need and preference. The researcher does not seek to explore individual information source horizons [22,23]. Thus, the researcher uses the term information environment, which he approaches from two viewpoints. First, he examines it among other information sources and second, he takes a closer look at the information sources on the Internet.

This paper examines cultural differences and cultural implications as well, in information behaviour from the viewpoint of information seeking [24]. The researcher considers information seeking as a part of everyday-life for students in an information environment [25,26,27], and the concept of information practices as a sub-concept of information seeking. The researcher's perspective on the concept of information practices derives from the framework of some scholars [28] and is distinguished from the ideas of information practices presented elsewhere in literature [26].Some authors classify information practices into four different modes: active seeking, active scanning, and non-direct monitoring and by proxy as part of information management and evaluation. In this study the researcher applies two of these four information seeking practices for examination, namely, active seeking and encountering. Active seeking refers to situations in which a person looks for information with a particular question in mind, on the Internet. Encountering refers to situations in which a person comes across information on the Internet by chance [28].

The researcher claims that this kind of approach to information practices is appropriate in this study. Models of Web-based information behaviour support this assumption by suggesting that the Internet is not used as often as an information source for formal searches as it is for more unconditioned seeking behaviour. For example, some of these models were created by analysing everyday life users' use of the Internet [29]. The model indicates that the more a user consumes the information within the Internet, the more likely he or she is to explore more categories, navigate more sites within a category, use fewer search engines, use more Web pages within a site and use them relatively quickly. Also, the behavioural model of information seeking on the Web, which was developed within the work context by these authors [30], shows that even in a task-related environment the workers mostly used the modes of conditional viewing and informal search.

Even though information behaviour models usually fail to acknowledge information encountering, it is possible that some people do exploit it and may to some extent control it [31], or acquire information mostly in this way 
[32]. For the majority of Web users the Web provides a rich environment of information encountering opportunities [32]. Moreover, information encountering has been shown to be recognized by varying groups of people: Icelandic health information seekers [33], as well as Australian elderly people [34] and scholars [31] use both purposive information seeking and incidental information acquisition as a means of information seeking.

\section{Research Methodology}

The quantitative descriptive design method was used in this study. The method entailed a process of describing; analysing and interpreting the data collected that measured the perceptions of the students on culture and its impact on web-based information seeking. A Questionnaire designed in the Likert scale (frequency) was used to collect the data from the 156 respondents from the Post Graduate Department of the Faculty of Business at Solusi University in Zimbabwe. A questionnaire is an instrument comprising of a series of questions that are filled in by respondents. This target group was chosen to ensure that the respondents had easy access to the Internet and to increase the probability that they were used to dealing with the Internet. The respondents were asked to indicate their answers by ticking the appropriate scale from 1 to 5 . Table 1 shows the evaluation and scoring of the questionnaires. The questionnaire covered the following key diagnostic areas and their variables: (1) Cultural sensitivity-tradition practices, beliefs, norms and values; (2) Internet skills-knowledge on how to browse and explore the on line information platforms, and (3) Information environments-internet connectivity and accessibility.

Table 1. Evaluation and Scoring of Questionnaires

\begin{tabular}{|c|c|c|c|}
\hline $\begin{array}{c}\text { Rating } \\
\text { Scale }\end{array}$ & $\begin{array}{c}\text { Response } \\
\text { option }\end{array}$ & $\begin{array}{c}\text { Mean } \\
\text { interval }\end{array}$ & $\begin{array}{c}\text { Verbal } \\
\text { Interpretation }\end{array}$ \\
\hline 5 & $\begin{array}{c}\text { Strongly } \\
\text { Agree }\end{array}$ & $4.51-5.00$ & Very Strong \\
\hline 4 & Agree & $3.51-4.50$ & Strong \\
\hline 3 & Uncertain & $2.51-3.50$ & Moderate \\
\hline 2 & Disagree & $1.49-2.50$ & Weak \\
\hline 1 & $\begin{array}{c}\text { Strongly } \\
\text { Disagree }\end{array}$ & $1.00-1.50$ & Very weak \\
\hline
\end{tabular}

This empirical study, based on structured questionnaire and convenience sampling technique consisted of postgraduate university students at Solusi University in Zimbabwe as both population and sample. That is, the sample consisted of all MBA (Master of Business Administration) and PGDBA (Postgraduate Diploma in Business Administration) students in the Faculty of Business at Solusi University $(N=156)$. See Table 2 below for the breakdown of the distribution of the respondents according to gender per programme.

Table 2. Distribution of respondents by gender per programme

\begin{tabular}{|c|c|c|}
\hline Table 2. Distribution of respondents by gender per programme \\
\hline Programme & Gender & \\
\hline MBA & Male & Female \\
\hline PGDBA & 99 & 41 \\
\hline Total & 11 & 5 \\
\hline
\end{tabular}

The survey began with questions about the respondents' background information regarding demographic characteristics such as age, and sex. Included in the background information section of the instrument was an assessment of Internet skills of the respondents and the average time they spend on the Internet each week. Next, the information sources used and preferences with regard to these indicated by the amount of use were elicited with closed questions.

Web-based information seeking was examined through the frequency of active seeking and/or accidental encountering. After this, the respondents were asked whether they sought or encountered information on various, stated course programme topics. The Web-based information source environment was examined by asking about the types of sites and other on line related services used.

The data were analysed with SPSS 17.0 for Windows. The analysis consisted of a calculation of distributions, a dependency analysis using cross-tabulations and Chisquared tests and, on one occasion, Fisher's exact test between background variables and other variables separately. An e-Information literacy variable was constructed as a mean variable from attitude questions regarding e-Information literacy and this was analysed with Mann-Whitney dependency analysis. The findings were considered significant at the level $p=.005$ or lower.

\section{Analysis of Data}

The data were gathered from 156 postgraduate students from Solusi University, Zimbabwe. The response rate was $100 \%$. Of the 156 respondents $96.9 \%$ (151) were 28 to 45 years old. Only five respondents were over 45 years old. Of the 156 respondents $71 \%$ (110) were men and, of the 156 respondents $29 \%$ (46) were women. There was no statistically significant differences between the perceptions of respondents by $\operatorname{sex}\left(\mathrm{X}^{2}(1)=1.055, p=\right.$ 0.303). Thus the sample is similar in sex and also sufficiently similar in the age of respondents. However, there were statistically significant differences in the respondents' assessments of their Internet skills and cultural sensitivity according to gender and nationality.

Self-assessment of cultural sensitivity (\%) and Internet skills (\%) of the Solusi University postgraduate students (respondents).

Even though the assessment of the respondents (sample) by sex and age were quite similar, as most respondents assessed their health to be either average or good, the male respondents in the sample assessed their sensitivity to cultural norms or values statistically significantly lower than that of female respondents, especially those female coming from outside Africa $\left(\mathrm{X}^{2}(3)=13.0, p=0.005\right)$. It must be noted that earlier studies comparing Japanese, British and Finnish employees also showed that the Japanese assessed their cultural impact on information seeking status lower than the Finns or the British [35].

All female respondents in general estimated their Internet skills to be poorer than that of all male respondents in general $\left(\mathrm{X}^{2}(3)=101.65, p=0.000\right)$. Most of the male respondents considered their Internet skills to be good, but most of the female respondents assessed them to be satisfactory. In addition, over $25 \%$ of the male respondents assessed their Internet skills to be excellent, while the same share of the female respondents assessed them to be marginal. Such assessments of Internet skills of 
male and female postgraduate students do not differ from those reported in earlier research [36].

The difference in the assessments of the Internet skills is partially supported by the Mann-Whitney analysis of the e-Information literacy variable, which shows that in the developed world, assessment of e-Information literacy related skills are better than those in the developing world ( $p=.001)$. There was, however no statistically significant connection between the time spent on the Internet and the assessed Internet skills level in the sample according to Fisher's exact test $(p=0.127)$.

Information environments. The information environments were examined on a general level and on the Internet. There are culturally interesting and statistically significant differences in the general information environments of the male and female postgraduate Solusi University students.

Library, Book shops, lectures and the Internet as information sources (\%) for Solusi University postgraduate students.

In the use of the information sources most obvious differences were identified either in the categories 'a lot' or 'not at all'. For example, the female respondents acquired more information from the library $\left(\mathrm{X}^{2}(3)=23.62, p=\right.$ $0.000)$ and book shops and lectures $\left(\mathrm{X}^{2}(3)=8.44, p=\right.$ 0.037). The male respondents, in turn, acquired more information from lectures $\left(\mathrm{X}^{2}(3)=40.36, p=0.000\right)$ and the Internet $\left(\mathrm{X}^{2}(3)=10.87, p=0.012\right)$. The rates of Internet use for information seeking (female respondents $63.1 \%$, male respondents $94.5 \%$ ) are somewhat higher than reported in earlier research in other African countries $[14,33]$. Responses to the first statement regarding the trustworthiness of information sources also reveal that the female respondents trusted information obtained from the library books and lectures more than did the male respondents $\left(\mathrm{X}^{2}(3)=39.78, p=0.000\right)$.

The findings indicate that general information environments might differ depending on the gender of the respondent. The female respondents despite their origin acquired information through close interpersonal relationships and from printed media and the male respondents from professionals and electronic media.

Thus, characteristics of these male and female respondents` cultures may help to explain these differences. Females are more personal-centric and may tend to use official electronic media just in serious matters. For male respondents, by contrast, it may be more common also to use electronic media for almost all information needs. Therefore, it is interesting to examine the Web-based information sources of these two genders. The Web-based information environments were examined by use of different types of information sources, namely the type of source and information related interactive services.

Information source types $(\%)$ used by the Solusi University postgraduate students.

All types of sites were used more by the male respondents; however, the preferences regarding the use of these types are similar in both genders. A search engine was the most popular and chat the least popular type of information source in genders. It must be noted that the sites and search engines were used statistically significantly more by the male respondents of different origins than female respondents $\left(\mathrm{X}^{2}(1)=6.83, p=0.009\right.$ and $\mathrm{X}^{2}(1)=17.68, p=0.000$ respectively). The female respondents also seemed to use discussion forums significantly more than the male respondents $\left(\mathrm{X}^{2}(1)=\right.$ $21.27, p=0.000)$.

Over $10 \%$ of the male respondents also listed other types of sites in the open-ended questions. On these there is a clear tendency to acquire information from commercial sources, such as the Websites as well. Interestingly, Wikipedia was also mentioned by several respondents. The female respondents did not provide alternative sources, although all respondents were asked what types of sites they had found if they had used a search engine $(n=55)$ : encyclopaedic sites like Wikipedia had been used by $45.5 \%$ and private or e-commerce sites by $32.7 \%$ of respondents.

The Web-based information environment was also examined through the use of more interactive information sources, the Web-based or on line e-books and e-journals for example. The respondents were asked about their awareness and use of these services. At least $95 \%$ of the respondents were aware of all the services. Overall the male respondents were more aware of these interactive services on the Internet and used them more.

Interestingly, the male respondents reported that the interactive features of Websites made the information acquired more memorable only slightly more than the female respondents $\left(\mathrm{X}^{2}(3)=8.23, p=.041\right)$. To sum up, these findings suggest that there is not as much difference on the Web-based information environments of the different genders as there was in the general information environments.

Active seeking and encountering of Web-based information

The Web-based information practices of the respondents were identified by the frequency of either encountering or actively seeking of the information. The response options were: not at all (1), a few times a year (2), once a month (3) a few times a month (4), weekly (5), several times a week (6).

Encountering and active seeking of information (\%) by the postgraduate students of Solusi University, Zimbabwe.

There is a clear difference between the information practices examined in this study. Frequencies of Webbased information encountering are quite evenly distributed between the classes and also between the genders $\left(\mathrm{X}^{2}(5)=4.05, p=0.542\right)$. On the other hand, the distribution of active seeking is much more skewed: in both genders most of the active seeking occurs only a few times a year. This means that Web-based information is encountered more often than it is actively sought. In other words, the respondents tend to encounter Web-based information and deliberately seek it only when they are given assignments to do.

Although the frequencies of the active seeking are also quite similar, the difference in class "Not at all" is notable. The Chi-Square test could not be performed, but it is evident that the male respondents acquire more Webbased information by active seeking than do the female respondents. The distributions of the statement regarding the primary source for information also indicate that the male respondents seek information more on the Internet $\left(\mathrm{X}^{2}(3)=14.68, p=0.002\right)$. 
Web-based information practices were also examined through several information topics in management. There were statistically significant differences in the topics of quantitative analysis $\left(\mathrm{X}^{2}(1)=18.37, p=.000\right)$, strategy $\left(\mathrm{X}^{2}(1)=37.07, p=0.000\right)$ and operations $\left(\mathrm{X}^{2}(1)=8.11\right.$, $p=0.004)$, which the female respondents reportedly encountered more. The male respondents sought actively more information on quantitative analysis $\left(\mathrm{X}^{2}(1)=5.70\right.$, $p=0.017)$ and strategy $\left(\mathrm{X}^{2}(1)=9.31, p=0.002\right)$.

\section{Conclusion and Recommendations}

This study contributes to the field of Education particularly, e-learning and information technology by examining cultural differences between male and female postgraduate students of different origin at Solusi University, Zimbabwe, general and Web-based information environments, related information seeking practices and the topical areas of information content searched for. The study aimed to identify cultural differences in the information behaviour of male and female postgraduate students at Solusi University by conducting a questionnaire-based survey. The analysis focused on differences in the overall and Web-based information environments, in the information seeking practices of active seeking and of encountering and in their relation to topical areas of information in business management.

There are differences in the information environments examined on a general level and on the Internet by analysing the use of different types of information sources, namely, the type of source and the related interactive services offered by the source. At the general level statistically significant differences indicate that the female respondents used more intrapersonal sources and print media and the male respondents used more Web-based sources. The characteristics of male and female students' cultures may help to explain these differences. Female students are more personal-centred and reserved and may tend to use Web-based sources of information only for serious matters such as assignments writing. For male students, by contrast, it may be more common to use the Web services even for almost any information need.

The cultural differences regarding the Web-based information environments focused on the variety of information sources and the awareness of information services on the Web. Sites and other search engine centres were used statistically significantly more by the male respondents, who also used significantly more discussion forums.

The information practices examined in this study, active seeking and encountering, did not differ statistically significantly between genders. Despite this, the information practices in seeking Web-based information varied. The male respondents both actively sought and encountered Web-based information more often than female respondents, which is supported by the finding that male respondents obtain information more often from the Internet. Web-based information was actively sought by male more than female and the relatively high rates in encountering information in both gender samples indicate that information is well provided and easily accessed on the Web.
Statistically significant cultural differences were identified and they focused on the general information environments and topical areas of business management information. However, on the general level no statistically significant differences were identified in the use of the two types of information seeking practices examined in this comparative analysis. Therefore, more empirical studies are needed to identify in more detail the effect of cultural issues on Web-based information behaviour and to improve the reliability of the findings by applying more elaborate research methods such as Grounded Theory.

\section{References}

[1] Rowlands, I, Nicholas, D, Williams, P, Huntington, P, Fieldhouse, M, Gunter, B, Withey, R, Jamali, H.R, Dobrowoiski, T. Y, and Tenopir, "The Google generation: the information behaviour of the researcher of the future", Aslib Proceedings 60(4), 290-310, 2008.

[2] O'Reilly, T 2005, "What is Web 2.0?" Sebastopol, CA: O'Reilly. Retrieved August, from http://oreilly.com/Web2/archive/what-isWeb-20.html, Archived by WebCite@ at http://www.Webcitation.org/5u9jRqwD8, 2009.

[3] Askola, K, and Huotari, M, L, "University students as health information seekers on the Internet. In P. Bath, G. Petterson and T. Steinschaden, (Eds.), Evaluation and implementation of e-health and health information iniatiatives: international perspective", Proceedings of the 14th International Symposium on Health Information Management Research - ISHIMR 2009. (pp. 171-180). Kalmar: University of Kalmar, 2009.

[4] Lemire, M, Paré, G, Sicotte, C, and Harvey, C, "Determinants of Internet use as a preferred source of information on personal health", International Journal of Medical Informatics, 77(11), 723-734, 2008.

[5] Tian, Y.Y, and Robinson, J.D, "Incidental health information use on the Internet", Health Communication, 24(1), 41-49, 2009.

[6] Rains, S.A, "Seeking health information in the information age: the role of Internet self-efficacy", Western Journal of Communication, 72(1), 1-18, 2008.

[7] Norman, C, and Skinner, H, "eHEALS: the eHealth literacy scale", Journal of Medical Internet Research, 8(4), e27. Retrieved August, 2009 from http://www.jmir.org/2006/4/e27/[Archived by WebCite ${ }^{\circledR}$ at http://www.webcitation.org/5uvPmPWKb], 2006.

[8] Kakai, H, Maskarinec, G, Shumay, D.M, Tatsumura, Y, and Tasaki K, "Ethnic differences in choices of health information by cancer patients using complementary and alternative medicine: an exploratory study with correspondence analysis", Social Science \& Medicine, 56, 851-862, 2003.

[9] Peña-Purcell, N, "Hispanics' use of Internet health information: an exploratory study", Journal of Medical Library Association, 96(2), 101-107, 2008.

[10] Ishida, E, Japanese culture: a study of origins and characteristics, Tokyo University Press, Tokyo, 1974.

[11] Heine, S.J, Kitayama, S, and Lehman, D, R, "Cultural differences in self-evaluation: Japanese readily accept negative self-relevant information", Journal of Cross-Cultural Psychology, 43(4), 434443, 2001.

[12] Caudill, W, Patterns of emotion in modern Japan, In R.J. Smith and R. Beardsley, (Eds.), Japanese culture: its development and characteristics. New York, NY, Wenner-Gren Foundation for Anthropological Research, 1963.

[13] Minami, H, Psychology of Japanese people, Tokyo University Press, Tokyo, 1971.

[14] Statistics Finland, "Internet users, spring 2001 to spring 2007, percentage of 15 to 74-year-olds by age group", Helsinki: Statistics Finland. Retrieved October, 2009 from http://stat.fi/til/sutivi/2007/sutivi_2007_2007-09-28_kuv_004_en.html, Archived by WebCite ${ }^{\circ}$ at http://www.webcitation.org/5uvQNTjAi, 2007a.

[15] Japan, Ministry of Internal Affairs and Communications 2009, "Communications usage trend survey in 2008" compiled, Tokyo: Ministry of Internal Affairs and Communications. Retrieved 14 November 2009 from 
http://www.soumu.go.jp/johotsusintokei/tsusin_riyou/data/eng tsu sin_riyou2008.pdf, Archived by WebCite $\AA$ at http://www.webcitation.org/5uvPeKhgt, 2008.

[16] Kimura, T, "Cyberspace as socio-psychological space: crosscultural comparison among the Japanese, Koreans and Finns", Journal of socio-informatics 1(1), 57-70. Retrieved 11 December, 2010 from http://www.soc.nii.ac.jp/jasi/eng/pdf/Journal_of_SocioInformatics_Vol1_No1.pdf, Archived by WebCite® at http://www.webcitation.org/5uvPBd4qD, 2008.

[17] Saperstein, S, Atkinson, N. Y, and Gold R, "The impact of Internet use for weight loss, Obesity reviews": an official journal of the International Association for the Study of Obesity, 8(5), 459-465, 2007.

[18] Williamson, D, A, "Two-year internet-based randomized controlled trial for weight loss in African-American girls", Obesity 14(7), 1231-1243, 2006.

[19] Jones, M, Luce, K.H, Osborne, M.I, Taylor, K, Cunning, D, Doyle, A.C, Wilfrey, D.E, and Taylor, C,B, "Randomized, controlled trial of an internet-facilitated intervention for reducing binge eating and overweight in adolescents", Pediatrics 121(3), 453-62, 2008.

[20] Wadden, T, A, "Lifestyle modification for the management of obesity", Gastroenterology, 132(6), 2226-38, 2007.

[21] Bennett, G.V, and Glasgow, R, E, "The delivery of public health interventions via the Internet: actualizing their potential", Annual Review of Public Health, 30(1), 273-292, 2009.

[22] Sonnenwald, D, H, "Evolving perspectives of human information behaviour: contexts, situations, social networks and information horizons", In T.D. Wilson, and D.K. Allen, (Eds.), Exploring the contexts of information behaviour: proceedings of the second international conference in information needs, seeking and use in different contexts. (pp. 176-190.) London: Taylor Graham, 1999.

[23] Savolainen, R. Y, and Kari, J, "Placing the Internet in information source horizons. A study of information seeking by Internet users in the context of self-development", Library \& Information Science Research, 26(4), 415-433, 2004.

[24] Wilson, T, D, "Human information behavior", Information Science 3(2), 49-55. Retrieved 11 December, 2010.

[25] Savolainen, R, "Everyday life information seeking: approaching information seeking in the context of way of life", Library and Information Science Research, 17(3), 259-294, 1995.

[26] Savolainen, R, Everyday information practices: a social phenomenological perspective, MD: Scarecrow Press, Lanham, 2008.

[27] Spink, A,Y, and Cole, C, "Everyday life information seeking research", Library and Information Science Research, 23(4), 301304, 2001 .
[28] McKenzie, P, J, “A model of information practices in accounts of everyday-life information seeking", Journal of Documentation, 59(1), 19-40, 2003.

[29] Huang, C.Y, Shen, Y.C, Chiang, I.P, and Lin, C, S, "Characterizing Web users' online information behaviour", Journal of the American Society for Information Science and Technology, 58(13), 1988-1997, 2007.

[30] Choo, C.W, Detlor, B, and Turnbull, D, "A behavioral model of information seeking on the Web: preliminary findings of a study of how managers and it specialists use the Web, In Cecilia M. Preston, (Ed.)", Proceedings of the 61st Annual Meeting of the American Society for Information Science. (pp. 290-302.) Silver Spring, MS: American American Society for Information Science and Technology. Retrieved August, 2009.

[31] Foster, A, and Ford, N, "Serendipity and information seeking: an empirical study", Journal of Documentation 59(3), 321-340, 2003.

[32] Erdelez, S, "Information encountering: a conceptual framework for accidental information discovery, In P. Vakkari, R. Savolainen and B. Dervin (Eds.), Information seeking in context", Proceedings of an international conference on research in information needs, seeking and use in different contexts, (14-16 August, 1996, Tampere, Finland). (pp. 412-241.) London: Taylor Graham (1997).

[33] Erdelez, S, "Information encountering: it's more than just bumping into information", Bulletin of the American Society for Information Science, 25(3), 1999.

[34] Pálsdóttir, Á, "Information behaviour, health self-efficacy beliefs and health behaviour in Icelanders' everyday life", Information Research, 13(1), 334. 2008.

[35] Statistics Finland, "Purposes of the use of the Internet in spring 2007, per cent of Internet users", Helsinki: Statistics Finland, Retrieved October, 2009 from http://stat.fi/til/sutivi/2007/sutivi_2007_2007-09-28_tau_001_en.html, Archived by WebCite ${ }^{\circledR}$ at http://www.webcitation.org/5uvQVdVdn, 2007b.

[36] Martikainen, P, Lahelma, E, Kagamimori, S, Sekine, M., Nishi, N, and Marmot, M, "A comparison of socio-economic differences in physical functioning and perceived health among male and female employees in Britain Finland and Japan", Social Science and Medicine, 59, 1287-1295, 2004.

[37] Saito, Y. Y, and Kimura, T, "Socio-cultural differences in the use of personal Web homepage and electronic communities among Japanese, Finnish and Korean youth", Journal of Socioinformatics, 1(1), 137-146. Retrieved March, 2010. 